\title{
Erving Goffman, su perfil y su obra
}

\author{
María Jesús Funes \\ Universidad Nacional de Educación a Distancia (UNED) \\ mfunes@poli.uned.es
}

\begin{abstract}
Resumen: Este artículo presenta una breve semblanza de Erving Goffman en la que se intercalan su biografía personal y académica con su formación y desarrollo como teórico e investigador. Determinados acontecimientos y circunstancias de su vida personal fueron relevantes en su selección de temas de estudio y en la atención prestada a los mismos por lo que se facilitan al lector los más relevantes. Parafraseando su propuesta de análisis dramatúrgico he titulado esta imbricación entre obra y personaje: El actor en el escenario, el escenario de su propia vida y el del contexto de la sociología de su época. La reflexión sobre su encaje en la teoría sociológica contemporánea desarrolla principalmente, aunque no solo, el debate sobre su dimensión estructuralista y/o interaccionista simbólica. Pero las aportaciones de este texto comparado con otras revisiones de su obra son dos: su contribución al estudio de las emociones, fundamentalmente el miedo como mecanismo de control social (la culpa como miedo/castigo interiorizado, la comunidad supervisora de la vida cotidiana, las instituciones...) y, desde ahí, la proximidad al trabajo de Foucault, rechazando la habitual crítica que se hace a Goffman como indiferente a las relaciones de poder.
\end{abstract}

Palabras clave: Control social, emociones, miedo, expectativas, posición social.

Abstract: This article presents a biographical and academic approach to Goffman as a man and as a researcher and creator of sociological theory. Taking into account that several circumstances and personal experiences had a huge influence on his decisions about issues to study and on the special attention put on them here we show some of the most relevant events. Following the dramaturgic metaphor, I have titled this part: The actor on the stage, the stage is his own life, the stage is the academic environment he lived in. The work about his position in the theoretical develop of contemporary sociology focuses mainly, but not only in his symbolic-interactionism even structuralism. However, the two relevant points of this work comparing with others review of his contribution are: the place gave to the analysis of emotions, mainly the study of the effects of fear in social live as 
social control mechanism (as inner guilty; community into every step of everyday live; institutions...); and second and from this point, the closeness to Foucault work, denying the frequent accusation of Goffman's indifference to power relationships.

Keywords: social control, emotions, fear, expectations, social position. 


\section{INTRODUCCIÓN}

Escribir un texto necesariamente breve sobre la obra de Erving Goffman, supone asumir las críticas que pueda despertar una revisión inevitablemente parcial. No es posible atender todos los aspectos relevantes de su trabajo, por lo que he optado por dedicar mucha atención a unos a costa de pasar de puntillas por muchos otros en lugar de hacer una mera indicación de todos o la mayor parte. He optado por no trabajar los más comentados y prestar más atención a otros que lo han sido menos. Esta difícil selección proviene de mi propia interpretación de su obra, tan discutible como cualquier apreciación subjetiva, pero en la que he tenido en cuenta el trabajo de otros investigadores que me han acompañado en la escritura de estas páginas y en cuyos textos sustento este artículo tanto como en las obras originales del autor a examen.

Adentrarse en su obra tratando de entenderla en conjunto implica aceptar confusiones y contradicciones que dificultan la tarea. Me refiero a la disparidad en los juicios de autores cercanos a él vital o intelectualmente, disparidad que puede producir, incluso, una sensación de imprecisión cuando no de fragilidad o falta de consistencia de su trabajo. Imagino que una fuerte personalidad y una consecuente libertad de pensamiento explican que pudiera desarrollar su labor prescindiendo del amparo de colectivos y escuelas. Su aportación al conocimiento del ser humano y de la sociedad son difícilmente discutibles y rara vez discutidos, pero resultan sorprendentes las críticas cruzadas en cuanto a su adscripción a corrientes o enfoques teóricos. Parece curioso que para unos sea uno de los más insignes representantes del interaccionismo simbólico mientras que para otros su postura contradice los principios básicos de esta corriente posicionándolo en el estructuralismo; opción que, a su vez, es rechazada por estructuralistas que sitúan su trabajo en la etnometodología rechazando esta dimensión estructuralista; que, asimismo, es duramente criticada por relevantes etnometodólogos. Mi intención es evitar los juicios intentando que el lector llegue a sus propias conclusiones retomando sus textos originales, si es que este artículo tuviera tan buenos efectos como estimular su (re)lectura.

\section{LA OBRA EN EL CONTEXTO O EL ACTOR EN EL ESCENARIO}

Aun cuando uno de sus biógrafos más reconocidos, Winkin (citado en Urteaga, 2010) lo presenta como un hombre que separaba radicalmente su vida de su obra, considero que una reseña biográfica, personal e intelectual resulta útil para ubicarnos en su pensamiento y su legado a la sociología. Nació en Mannville (Alberta, Canadá) en 1922 y falleció en 
1982 en Filadelfia (Pensilvania, Estados Unidos). Hijo de inmigrantes ucranianos de origen judío, afincados a finales del siglo XIX en Canadá, vivió de niño la ambivalencia de la integración y el rechazo, la aceptación matizada por la autopercepción del diferente, no sabemos si tanto como excluido dado el carácter integrador de la sociedad canadiense, pero conoció la experiencia de ser el otro, el nunca confortable sentimiento de la ajenidad.

Comenzó sus estudios de sociología en 1944 en la Universidad de Toronto donde entró en contacto con el pensamiento de los autores clásicos que serán centrales en su trabajo (Durkheim, Parsons, Simmel, Weber), siendo marcado desde los inicios por la visión antropológica de Radcliffe-Brown. En 1945 continúa sus estudios de sociología en la Universidad de Chicago donde conoció a Blumer quien le conectará con el pensamiento de Mead y el interaccionismo simbólico. En 1949 fue contratado por el Departamento de Antropología Social de la Universidad de Edimburgo, lo que intensificó la dimensión antropológica de su investigación, fundamentalmente por su estancia en una de las islas escocesas de Shetland en la que se dedicó a analizar la vida local. Fue la base de su tesis doctoral y el inicio de su observación detallada de la vida cotidiana. A su vuelta vivió un periodo en la Escuela de Chicago, cuya huella permanecerá a lo largo de su carrera en cuanto a los temas a estudiar: problemas sociales, sujetos marginales o en situación de dificultad y, en cuanto al método, por el refuerzo de la epistemología cualitativa. (Ritzer, 1993; Treviño, 2003; Urteaga, 2010; Mercado y Zaragoza, 2011).

En 1953 defiende su tesis doctoral Communication Conduct in an Island Community en la Universidad de Chicago. Ese mismo año contrae matrimonio con la hija de un influyente personaje de la burguesía de Boston, entrando así a formar parte de una familia prestigiosa y adinerada; al año siguiente nacerá su hijo y, poco después, la familia se traslada a Washington. En 1956 publica su primera obra relevante: The embarrassment and Social Organization. Durante su estancia en Washington vivió la experiencia que, probablemente, más marcó su carrera: su estancia como investigador en el National Institute for Mental Health Santa Elisabetta. Consiguió ser contratado como celador con el objeto de analizar, mediante observación participante, el comportamiento cotidiano de pacientes y personal sanitario, lo que dará lugar unos años después a su obra Asylums (1961). En 1958 Blumer le propone crear un departamento de Sociología en la Universidad de California en Berkley, donde será nombrado profesor en 1962 y permanecerá hasta 1968. Durante este tiempo formó parte de la Escuela de Palo Alto, donde trabajó con Bateson, cuya influencia se aprecia en su obra más sobresaliente de la segunda mitad de su vida: Frame Analysis (1974) y conoció la fenomenología y la lingüística estructural, ambas reconocibles en su trabajo teórico y desarrollo empírico.

De este periodo son algunas de sus obras más apreciadas, en 1959 se publica The Presentation of Self in Everyday Life, una de las más importantes de su carrera y donde 
desarrolla su propuesta de análisis dramatúrgico. Aparece, a continuación, Asylums, en 1961, consecuencia, como hemos visto, de sus investigaciones en el hospital psiquiátrico de Washington. Esta última obra tuvo gran influencia en el análisis de la desviación y la represión, en términos sociológicos, del funcionamiento de un tipo de instituciones que a parir de este momento serán instituciones totales, en el conocimiento de los procesos de institucionalización del orden social, pero también fue trascendental en términos psiquiátricos, ya que junto a la obra de otros autores como Foucault forma parte de la base teórica del movimiento de la antipsiquiatría. La antipsiquiatría se extendió por Europa y Estados Unidos en la década de los setenta y ochenta del siglo xx dando lugar a reformas trascendentales en el sistema psiquiátrico; supuso la desinstitucionalización de muchos enfermos mentales y una absoluta revolución en la consideración y tratamiento de la enfermedad mental, principalmente por su cuestionamiento del internamiento como herramienta terapéutica, algo que deja muy claro Goffman en un trabajo posterior: «The treatment most patients have received — hospitalization - has proven to be questionable indeed. Patients recovered more often than not, at least temporarily, but this seems in spite of ${ }^{1}$ the mental hospital, not because of it» (Goffman: 1969b; 357).

Fue una época brillante en lo profesional en la que comenzaba a ser reconocido nacional e internacionalmente, pero de gran amargura a nivel personal. Su esposa sufría los males de los enfermos que estudió y que la condujeron al suicidio en 1964. Lo que encontramos en sus libros sobre la relación con los enfermos mentales y los efectos en quienes les rodean procede no solo de sus investigaciones sino también de su propia experiencia. Se ve muy claro en una obra escrita varios años después The Insanitity of Place (1969b) donde presta mucha atención a los familiares y al rol que desempeñan tanto en el tratamiento de los enfermos como en la relación de éstos con la sociedad.

En el año 1963 publicó otra de sus grandes obras Stigma: Notes on the Management of Spoiled Identity. Durante este tiempo en California, vivió una productiva estancia investigadora en el Center for International Affairs de Harvard entre 1966 y 1967, donde incorporó a sus análisis la teoría de juegos depurando con ella su estudio de la interacción. Su última obra relevante es Frame Analysis (1974), en la que pergeñó un método de investigación que tendrá enorme éxito en diversos campos, especialmente en los de la comunicación, el comportamiento y el conflicto políticos².

${ }^{1}$ La cursiva es mía (nota de la autora).

2 En los estudios de la acción colectiva tiene seguidores como Benford, Snow y Hunt (2000), principalmente. También en autores de la teoría del proceso político como Tilly (2006) y Tarrow (1994). 
Su carrera terminó en la Universidad de Pensilvania donde trabajo desde 1968 hasta su fallecimiento en 1982. El año anterior, 1981, había contraído matrimonio y el mismo año de su muerte nació su hija, Alice. Curiosamente, ella que no conoció directamente la obra de su padre, es una digna heredera de su legado, ya que ha publicado diversas obras de impacto en una línea de investigación que, si bien hoy se denomina etnografía política, sigue la estela teórico-metodológica de su padre. En la actualidad, es profesora de la Universidad de Wisconsin. La vida de Goffman estuvo más centrada en la investigación que en la docencia y fue más analista que creador de discípulos; no formó escuela y se mantuvo en las fronteras de disciplinas y movimientos intelectuales. Sin embargo, murió siendo presidente de la American Sociological Association lo que permite relativizar la imagen de él como un hombre alejado de los círculos de la profesión (Urteaga, 2010).

\section{ENCAJAR «LA PIEZA» EN EL ROMPECABEZAS}

Tratar de ubicar su obra en una corriente teórica o, cuando menos, en una trayectoria lineal no es tan fácil como en principio podría parecer. Todos le conocemos como el «padre de la microsociología» del análisis de la vida cotidiana y las relaciones cara a cara, pero más allá de esto, si queremos vincularlo con escuelas de pensamiento la cosa se complica. Autores como Alexander (1992), Mercado y Zaragoza (2011) y Caballero (1998) consideran que su legado ha de entenderse como desarrollo y profundización del interaccionismo simbólico. Sin embargo, otros autores como Ritzer (1993) subrayan también su impronta estructuralista. Su forma de analizar la interacción y los significados que emitimos y recibimos en la comunicación cara a cara denotan la huella indudable del «otro generalizado» de Mead (al que cita con frecuencia): cada cual construye su propio yo basándose en la información de sí mismo que recibe de los otros, y estos otros devuelven al sujeto la imagen que éste ha emitido de sí mismo en el acto comunicativo, imagen inevitablemente transformada y procesada desde la peculiar forma de entenderla de estos «otros receptores»: puro interaccionismo simbólico, ¿no? Pues parece que no. Las críticas recibidas por autores que se vinculan a esta línea teórica, las propias críticas de Goffman a estos pensadores, y su intención manifestada de no querer ser reconocido como parte de ella, nos obligan a cuestionar esta clasificación. El trabajo de Urteaga (2010) sobre textos de Gonos y Denzin y Keller le sitúa «en las antípodas del interaccionismo simbólico» por su impronta estructuralista y formalista, apoyándose en que para Goffman: «Los actores son soportes de las estructuras sociales preexistentes» (2010:157). 
Pero, para enriquecer el debate sobre la huella del interaccionismo simbólico y el estructuralismo, podemos incluir una corriente más, la fenomenología y su deriva en el construccionismo. No se puede negar la cercanía de Goffman a este planteamiento. De ello es buen ejemplo su obra de 1959 La presentación de la persona en la vida cotidia$n a$, donde concede una importancia crucial al concepto de definición de la situación, en el que las dos dimensiones nucleares de la fenomenología son evidentes: la centralidad de la subjetividad y la capacidad del sujeto para construir realidad. Desde esta perspectiva puede entenderse que Goffman está atribuyendo una capacidad interpretativa al sujeto que le aleja de las imposiciones estructurales. Sin embargo, para dilucidar cuánto hay de construccionismo y/o estructuralismo en su pensamiento conviene recordar la impronta durkheimiana (más del Durkheim estructuralista que del funcionalista) lo que hace improbable que reconociera el margen de libertad individual que consideran los fenomenólogos (Herrera y Soriano, 2005).

Centrarnos en el concepto «libertad individual» al analizar la huella etnometodólogica de Goffman nos sirve para contrastar los principios de esta escuela con la visión del «yo en las estructuras» del autor a examen. El peso de las estructuras es doblemente «pesado» en Goffman. En su forma de entender el condicionamiento de la definición de la situación no quita importancia a la capacidad de acción/decisión del sujeto, pero subraya la fuerza inmanente de determinados procesos y de las posiciones sociales. Ahora bien, frente a los estructuralistas clásicos, Goffman reconoce al individuo una capacidad de gestión de los límites en cada situación (límites situados en acciones situadas ${ }^{3}$ ). Pone como ejemplo los rituales y las rutinas que aportan información estereotipada, que se repite. Y es precisamente por esta repetición, que permite observar los actos e interpretarlos, por lo que el actor/sujeto puede anticiparse a ellos, teniendo un margen para guiar y reconducir su conducta $(1959 ; 1963)$. Desde el punto de vista teórico es sugerente analizar desde la etnometodología la tensión entre estructuralismo y constructivismo, pero al hacerlo no podemos ignorar las críticas «de» y los desencuentros «con» los etnometodólogos. En particular con Garfinkel y Sacks (Díaz, 2000) y el rechazo del propio Goffman a buena parte del trabajo de éstos, entre otros a su análisis conversacional ${ }^{4}$.

Desde mi punto de vista, el giro de Goffman se ve claro en dos obras de 1969: Strategic Interaction y The Insanity of Place. En el primer caso porque añade el concepto 'strategic', es decir, el sujeto puede planificar estrategias de acción procesando la infor-

\footnotetext{
${ }^{3}$ Imposible no recordar aquí las acciones situadas de Mills en su «Acciones situadas y vocabularios de Motivos» (1964).

${ }^{4}$ De nuevo, opiniones encontradas, Collins (en Ritzer, 1993) atribuye protagonismo a Goffman en el desarrollo de la etnometodología, incluso del análisis conversacional.
} 
mación que recibe de las situaciones (los escenarios). Y en ambas obras porque describe la fuerza de los contextos teniendo en cuenta la polisemia de los signos: un mismo signo, en función del lugar, situación, escenario, donde se emita tendrá un significado u otro. Es decir, subraya el condicionamiento de la posición, una posición no aislada sino situada en una retícula de posiciones ${ }^{5}$ : «The insanity of place is a function of position» (1969b: 380).

Por terminar este apartado, si a todo ello añadimos su desarrollo de los clásicos, Durkheim, por supuesto, pero también Weber y Simmel y la inteligente integración de la lingüística estructural de autores como Wittgenstein y Chomsky, podemos cerrar brindando por el valor de la multidisciplinaridad más que incomodarnos por no poder encajar con precisión la pieza «Goffman» en el puzle de la teoría sociológica contemporánea. Un interaccionista simbólico que aplica el condicionamiento de las estructuras siguiendo el análisis sintáctico de los lingüistas y que subraya el peso de las formas acercándose a una sociología formalista de corte simmeliano; un precursor de la semiótica ${ }^{6}$ que consigna la huella de las emociones y los conflictos (indomesticados) de la libido siguiendo a Freud. Un durkheimiano que frente a la visión determinista del maestro vislumbra, desde la etnometodología, márgenes de libertad, precisamente en esos rituales que fijan y pautan los comportamientos, y que ambos (Durkheim y Goffman) interpretan como anclajes sociales que someten, pero en los que nuestro autor encuentra opciones de salida, de evasión, «precisamente» porque su carácter estereotipado permite «jugar» con ellos y sortearlos. ¿Confusión o riqueza? ¿Imprecisión o apertura de miras y vigor en la complejidad? Cada cual podrá llegar a sus propias conclusiones.

Como resultado de mi propia revisión me convencen más, sin compartirlas del todo, las críticas al método que a los aspectos teóricos, las opiniones sobre: debilidad metodológica, falta de rigor, tendencia a la improvisación en los ejemplos, a mezclar lo inventado con lo real, hechos probados con escenas cinematográficas, viñetas, relatos de novelas; su preferencia por lo episódico y anecdótico frente a lo trascendental, exceso de descripción y pobreza del análisis. Así lo ven Schegloff, Garfinkel, Sacks, Cicourel, según Díaz (2000). A mí, sin embargo, me sigue convenciendo la idea de que cada escena (real o ficticia) reproduce una parte del orden social general porque ninguna interacción es casual, ni espontánea ni «a» normativa, puesto que es resultado de decisiones concretas.

\footnotetext{
${ }^{5}$ De nuevo, Mills (1964) y el trabajo de Beltrán en La realidad social (1991).

${ }^{6}$ Siguiendo a Hernández (1981).
} 
Cada sujeto elige entre las opciones que tiene a su alcance como consecuencia de su situación; y su «situación» es posición. Y aquí me parece oportuna, por lo clarificadora, la interpretación de Charles Tilly de esta idea aplicada a los repertorios de contestación en su análisis del conflicto y de las relaciones cara a cara. Los sujetos y los grupos eligen unas $u$ otras acciones entre las pautas de expresión e intercambio disponibles en su medio, siempre limitadas a cada situación y experiencia. Porque en la toma de decisión que precede a una acción se reproduce, como un microcosmos, la vida social que conocemos; porque nuestra capacidad de imaginación no es infinita ni a-social. Brillante, en este sentido, la aportación de Tilly al estilo goffmaniano en la última etapa de su vida que encontramos en su obra Why: What happens when People Give Reasons and Why $(2006)^{7}$.

\section{LO MICRO (LO MACRO) Y LA INTERPRETACIÓN DE LAS EMOCIONES}

Goffman dedicó su trabajo investigador a lo pequeño, lo cercano, a lo que todos tenemos acceso, lo que vemos y vivimos cada día. El objeto de la ciencia está en la calle a la vista de todos: al hacer la compra para la cena, en una parada de autobús o en una conversación entre dos amigos en un parque. No es necesario internarse en un laboratorio ni consultar complejas series estadísticas o archivos rigurosamente clasificados. No, la sociología es algo más simple y, por ende, más complejo porque, si está en todo, igualmente puede perderse en ese todo. Parece que propone una sociología que todos podríamos hacer. En gran medida, es por ello por lo que se le valora (y critica) por adaptar el foco del análisis científico a episodios (aparentemente) banales reconociéndoles valor gnoseológico.

Con Goffman aprendemos una forma de hacer sociología que comienza por educarnos la mirada, nos enseña a posicionarnos ante lo que queremos conocer, situándonos en un paso previo: ¿desde dónde miramos?, ¿desde dónde debemos mirar? El observador debe desarrollar unas antenas particularmente sensibles para detectar la trascendencia sociológica de las menudencias. Ni lo más pequeño, ni lo más cotidiano son despreciables, nada puede darse por descontado o ya sabido, hasta lo aparentemente intrascendente incluye y representa el orden general (o una parte). Interpreta los hechos a los que no se suele prestar atención como síntomas de los mecanismos estructurales que se imponen en cada acto (Scheff, 1990: 36; Caballero, 1998: 142). Estudiar lo pequeño

\footnotetext{
${ }^{7}$ Desarrollado por Aguilar y Funes (2011 y 2016) en «La atención a lo micro: ¿un Tilly dramatúrgico?».
} 
supone estudiar lo grande, porque visibiliza lo que no se suele ver. Para quien sea capaz de leerlo, estos actos micro hacen visible lo invisible.

Nuestro autor profundiza el concepto weberiano de acción social como acción «que tiene en cuenta a otros», donde esos «otros» juegan un papel determinante, pero no solo desde la perspectiva del «otro generalizado» de Mead y de la dimensión moral de Weber $^{8}$ (que también) sino en tanto que representan las normas sociales: la sociedad reproduciéndose a sí misma en cada reconocimiento mutuo. Porque Goffman añade las expectativas que son obligaciones mutuas que recrean y sostienen el orden social en su carácter impositivo. Éstas parten de la previsión de los juicios de los otros y actúan como guías para ajustar la conducta. La toma de decisiones cotidiana funcionalista como en cualquier economía de escala aplicando un análisis de coste/beneficio (no explícito), tratando de perder/sufrir (rechazo, críticas) lo menos posible y de ganar/recibir (aceptación y reconocimiento) cuanto más mejor. Es decir, en el juego de la interacción conectamos nuestros deseos con lo que intuimos que los demás esperan de nosotros: nuestras expectativas del exterior con las que prevemos que ese exterior tiene de nosotros, adoptando roles, utilizando máscaras que cambian en función de la escena (circunstancia) intentando minimizar los riesgos de sufrimiento o fracaso (Strategic Interaction, 1969a; Stigma, 1963).

El autor distingue dos estructuras comunicativas: una consciente y planificada, otra inconsciente y, por lo tanto, no controlada (Strategic Interaction, 1969a). Esta segunda contiene más valor informativo al no estar bajo el dominio racional del actor (Scheff, 1990: 6) ${ }^{9}$. Continuamente estamos emitiendo mensajes que aportan información sobre nosotros y buena parte de ellos no forman parte de nuestro guion consciente, no responden a decisiones, sino que proceden de esa segunda estructura comunicativa. Ello pone en evidencia esferas de vulnerabilidad, territorios expuestos no defendidos por la racionalidad que trata de minimizar el riesgo del que hablábamos anteriormente (Stig$m a, 1963)$. Y aquí enlazamos con la cuestión de las emociones. La segunda estructura está dominada por las emociones y éstas informan de las intenciones y deseos del sujeto en mayor medida que la comunicación del primer nivel. En esa especie de trastienda se encuentran el miedo a ser rechazado, la sensación de amenaza, inseguridad, emociones que, como señala Sheff (1990: 7), provocan reajustes en los modelos de acción. Si el investigador las detecta puede comprender la intrahistoria, el backstage de la situación.

\footnotetext{
${ }^{8}$ En cuanto al carácter moral y su diferencia con el planteamiento weberiano véase Gouldner (1979).

${ }^{9}$ Las huellas de Freud en esta interpretación de la comunicación son innegables.
} 
En este análisis de la dimensión emotiva, la cuestión de la legitimidad se revela como nuclear, fundamentalmente porque la legitimidad la otorgan los otros, lo que muestra el orden y la jerarquía subliminal que rige la comunicación. La legitimidad se entiende como una ratificación recíproca, mis comportamientos y actitudes son legítimos en función del juicio externo que yo doy por válido; $\mathrm{y}$, a la vez, yo juzgo el comportamiento de los otros del que se deriva su legitimidad; de este modo están tan vinculados ellos a mí como yo a ellos. Son estos juicios y los comportamientos que de ellos se derivan los que provocan emociones, tanto negativas: odio, miedo, vergüenza, ante un previsible rechazo; como positivas: confianza, seguridad y aceptación que tornan en bienestar y alegría, cuando los otros muestran que aceptan como legítima mi comunicación y, en consecuencia, me aceptan a mí. El orgullo y la vergüenza, emociones a las que dedica especial atención, son las que mejor explican la comunicación social como reproductora del orden, de los límites, los márgenes y, por ende, de los vínculos y la vida social (Stigma, 1963).

La utilización de las emociones como mecanismo de control social se estudia en particular en Internados (1961/1994) y en Estigma (1963/1998). Provocar emociones (negativas y positivas) es más práctico que aplicar sanciones, más barato, y genera menos rechazo. Pero, además, es más eficaz porque supone instaurar un sistema punitivo invisible que consigue resultados de conformidad más altos que los reglamentos formalizados, ya que interioriza la penalización (la culpa). Y ésta es la manera en que el control social se ejerce en la interacción, donde todos controlan a todos, anticipando la vergüenza o el miedo a ser expulsados o no queridos, y el orgullo de ser reconocidos, queridos. Visto de este modo, las sanciones formales serían, en buena medida, prescindibles. La anticipación a las mismas puede ser suficiente si el miedo a caer en la ignominia o en la censura evitara, por sí mismo, comportamientos potencialmente punibles (Scheff, 1990: 74). En este sentido Goffman señala con qué facilidad leemos la mente de los otros y sustentamos nuestras relaciones en ratificaciones recíprocas que hacemos permanente e inconscientemente (Interaction Ritual, 1967: 34).

Como vemos, su análisis de lo micro tiene más que ver con la perspectiva durkheimiana que con la de Bateson o sus discípulos (sin negar la influencia de éstos), ya que no se queda en el suceso o situación, sino que desenmascara el carácter impositivo de lo social. Dicho de otro modo, evidencia las relaciones de poder, si bien no en términos tan expresivos como los foucaultianos, por ejemplo, pero igualmente muestra el imperativo social que determina los comportamientos. Como señala Freidson en Celebrating Erving Goffman: «Goffman's early work is focused on the individual self, in a world that at once creates and oppresses it». (1983: 359).

Esta crítica de la sociedad sancionadora es muy clara cuando habla de quienes la sufren más intensamente: los estigmatizados, los locos, los marginados, pero que no son 
los únicos. De hecho, esa es una de las virtudes de su obra: al distinguir entre el estigmatizado y el que estigmatiza, el loco y el cuerdo, está mostrando el peso de la norma sobre todos. Como señalan Herrera y Soriano (2005: 191) la comunicación se desarrolla en la tensión de los sujetos entre el deseo y la necesidad del individuo particular y las exigencias de la convivencia social ${ }^{10}$. El trato dado a estos sectores más débiles representa la defensa que la sociedad hace de sí misma — de sus propias contradicciones de las que ellos no son sino síntomas - generando instituciones que los aíslen del resto, de los cuerdos, los perfectos, poniendo en evidencia la fragilidad social, el miedo a sucumbir ante la diferencia.

Las instituciones totales, a fuerza de subrayar su excepcionalidad, nos permiten entender la normalidad y los estigmatizados ayudan a entender a los normales; porque todos son comportamientos adaptativos ante el control social. De hecho, un capítulo de Estigma se titula «El desviado normal»: «El problema ya no consiste en saber si una persona tiene experiencia con un estigma, porque de hecho la tiene, sino en saber cuántas son las variedades de esa experiencia» (Estigma, 1998: 151). La reducción metonímica que expresa la estigmatización (no existe la persona, solo el rasgo que la singulariza), o la transformación del «yo único» en el «interno anonimizado» son solo estrategias extremas del control en estado puro. En un juego de suma cero, los estigmatizados no existen sin los estigmatizadores, al modo del análisis de las relaciones asimétricas de la Escuela de Palo Alto, son parte de un sistema que se retroalimenta en el juego de los opuestos.

\section{LA MORAL Y LAS RELACIONES DE PODER: UNA APROXIMACIÓN A FOUCAULT}

Goffman ha sido criticado por ser complaciente, o indiferente, con el poder al no hacer una crítica directa del mismo y actuar como un analista de la clase media acomodada norteamericana, casi como si de un narrador costumbrista se tratara. Al tiempo, se cuestiona la moralidad de sus planteamientos al describir en su análisis dramatúrgico las decisiones instrumentales que guían a los sujetos a cambiar de «máscara» en función de las circunstancias. Como dice Gouldner: «Según Goffman, lo que en este mundo valga un hombre depende de sus apariencias y no de sus talentos, capacidades o logros (...)

${ }^{10}$ Una nueva forma de entender el dilema de la Antígona de Sófocles aplicado a nuestra realidad actual. 
La moralidad misma se ha convertido en una cuestión de prudente conveniencia» porque «Lo que cuenta no es que los hombres sean morales, sino que lo parezcan» (1979: 349,350 y $351^{11}$ ). En este sentido, Gouldner afirma que con su trabajo trivializaba la sociología: «es la sociología de la venta de almas» (352). Caballero, en su estudio de 1998, cuestiona de manera brillante estas tesis de Gouldner, al igual que Freidson, cuando señala: «Goffman's work is intensely moral in character, marked by a passionate defence of the self against society» (1983: 359).

Terry Young señala que los pensadores ideológicamente de izquierdas le acusan de analizar las relaciones humanas de manera despolitizada, tan descriptiva que ignora las relaciones de poder, estatus y clase. Ciertamente, Gouldner ha pasado a la historia como ejemplo de compromiso con una sociología crítica y no es éste el caso de Goffman. Sin embargo, la fuerza corrosiva de alguna de sus obras me lleva a cuestionar estas interpretaciones. Resulta difícil no ver el punto de crítica en su análisis de la destrucción del yo en las instituciones totales, en la sumisión de internos y trabajadores a unas normas que los cosifican y anulan su libertad. Difícil, también, no apreciar una mirada moral en su disección de la voracidad de las instituciones que destruyen a los sujetos o en el sometimiento mediante la caracterización del estigmatizado. Evidentemente, se puede considerar una visión de la determinación más durkheimiana que foucaultiana o marxista, pero solo una lectura superficial puede calificar su obra de tibieza o trivialización.

En este punto, poner en paralelo su trabajo con el de Foucault me permite resaltar lo que considero la parte más brillante de su obra. Goffman y Foucault fueron contemporáneos y sus trayectorias investigadoras resultan cercanas, un paralelismo poco explorado salvo interesantes excepciones (Moreno, 2015; Caneda, 2012). En 1961 se publican Internados de Goffman e Historia de la locura en la época clásica de Foucault; en 1963, El nacimiento de la clínica de Foucault y Estigma y Behaviour in Public Places de Goffman; en 1966, Las palabras y las cosas de Foucault y en 1967 Interactual Rituals: Essays on Face-to-Face Behavior de Goffman. En 1969, Goffman publica The Insanity of the Place; en 1975, Foucault Vigilar y Castigar...

El estudio del sistema carcelario, los hospitales, los sistemas represivos y la construcción de la locura de Foucault tienen relación con el estudio de Goffman de los sistemas de internamiento psiquiátrico, las instituciones totales, o la discriminación entre sanos y enfermos. La construcción socio-normativa del demente en el Foucault de $E l$ nacimiento de la clínica y la construcción socio-normativa del loco en el Goffman de Internados son bien similares. Pero también es comparable la construcción del contra-

\footnotetext{
11 Las cursivas son de Gouldner.
} 
rio, o de su espejo: el «sano» interpretado por el carcelero en Foucault o el personal sanitario en Goffman, que en ambos casos son el contrapunto que permite que existan los primeros. Son expresiones del control social institucionalizado y normalizado que cristaliza en la creación de barreras físicas, en rituales de desposesión, en penalidades físicas como la tortura, el electroshock, o la negación sustancial que relega a unos sujetos a la ignominia de su «ser sancionados/anulados» diluyendo su dimensión de seres humanos.

Tanto da el lenguaje de la clínica o el de la prisión, la comunicación verbal o la no verbal, las miradas y los gestos en los rituales de transformación y anulación son similares. Los internos dejan de ser seres humanos para ser presos o locos, ...o deformes. Pero, es más, el mero hecho de cuestionar que alguien esté en el mundo de los cuerdos/ normales, incluso no estando internado, fragiliza todo su ser porque pone en duda la adecuación a esa normalidad que da tranquilidad, que evita la vergüenza de la exclusión. Y aquí se manifiesta que el eje de los comportamientos se articula en torno a una emoción poderosa: el miedo; dado que mi legitimidad proviene de los otros, es el miedo a ser juzgado como distinto, a la exclusión o a la burla, lo que produce la normalidad deseada. Esto es muy claro en Estigma: los otros están ahí para recordarme mi estigma o la permanente posibilidad de ser estigmatizado y caer en, o bordear, la muerte social.

Vigilar y Castigar (1975) y la Microfísica del Poder (1979) explican la evolución de los procesos y mecanismos de control: la sustitución de la tortura por la vigilancia y el control internalizado, la racionalización del castigo y su transformación en medios más sofisticados. La explicación de la eficacia progresiva en el ejercicio del poder mediante la racionalización, la burocratización y la tecnologización es bien parecida a lo que explica Goffman en The Insanity of Place (1969b: 363) cuando distingue entre el control personal (interiorizado que olvida su origen externo), el control informal en cualquier escena rutinaria y, por último, el control formal, el de las normas, las leyes, las sanciones. Goffman atribuye la máxima virtualidad disciplinaria al primero: «The individual refrains from improper action by virtue of acting at his own policeman» (1969b: 363). La descripción del control informal en la cotidianeidad parece un adelanto de la idea de capilarización del poder de la Microfísica del Poder de Foucault (1979).

Al igual que Foucault, Goffman (1969b) identifica la comunidad como entidad controladora desenmascarando las relaciones de poder subyacentes al mostrar los rituales de segregación en las instituciones totales mediante los que éstas defienden al resto del loco/malvado/estigmatizado. Es la comunidad la que crea y sostiene a través de determinadas prácticas las expectativas y obligaciones que delimitan los campos de lo consentido y lo no consentido, lo prohibido, lo denigrado, lo maldito. También ambos autores señalan la ciencia como compañera inseparable en esta labor. Los doctores, al igual 
que los carceleros, la judicatura o la psiquiatría, representan la sociedad que (ordena) margina y excluye. La ciencia está al servicio de la comunidad y no del paciente, es el instrumento que permite y justifica la segregación de «los otros» creando una alteridad culpable. Esto que es muy claro en Foucault también lo es en Goffman si recordamos que distingue tres tipos de causas para la enfermedad mental: orgánicas, psicogenéticas y, las que más nos interesan aquí: situacionales. En estas últimas la secuencia es la siguiente: $1^{\circ}$ ) la sociedad produce el mal, $2^{\circ}$ ) la identificación de la patología es la forma mediante la que la ciencia legitima la estigmatización, y, $3^{\circ}$ ) la sociedad se defiende de lo que ha producido con el apoyo imprescindible de la ciencia (1969b: 362).

Termino esta reflexión mostrando dos evidencias que contradicen la crítica de Gouldner y otros autores en cuanto a su tibieza en términos políticos o ante las desigualdades sociales. Al hablar de las causas situacionales de la enfermedad mental las califica como «more a political issue than a medical one» (1969b:363). Y, en cuanto a su supuesta indiferencia ante las diferencias de clase, señalo dos ejemplos de lo contrario. En la misma obra aclara que, dado que ha estudiado las condiciones de las familias de clase media o alta estadounidense, sus resultados son aplicables a dicha posición social, porque: «The insanity of place is a function of position» (1969b:380); y en Estigma, explica: «La discriminación basada en el estigma esconde con frecuencia otro tipo de discriminaciones menos aceptables (reconocibles) como la marginación por razón de clase» ${ }^{12}$ (1998: 15).

En una de sus últimas intervenciones en público, Goffman señala: «el problema radica en encontrar las mediaciones entre el orden macrosocial y las situaciones de interacción cara a cara» (1983). Propongo dos interpretaciones de estas mediaciones en su trabajo. La primera podemos encontrarla en su estudio de las emociones que surgen en lo cotidiano, lo pequeño (nivel micro), que según él evidencian la existencia de las estructuras (dimensión macro) en su función de control. Visto así, cualquier comportamiento que provoca emoción desvela su relación con alguna estructura no visible, con alguna norma que puede ser explícita y visible o implícita y oculta. Y en ello no solo me baso en el análisis hasta aquí realizado sino en Manning (2000) que en su obra de «Credibility, Agency, and the Interaction Order» utiliza la distinción de Giddens entre estructura y agencia para explicar esta conexión, donde la agencia estaría representada por las emociones y el orden macro por la estructura. Según Manning (2000), Giddens sitúa a Goffman en la teoría de la estructuración valorando su aportación para entender este vínculo. Pero también podemos encontrar este vínculo entre lo micro/lo concreto y lo macro/lo abstracto en su Frame

\footnotetext{
12 Las cursivas son mías, con las que pretendo resaltar el argumento.
} 
Analysis. Esta propuesta analítica es una elaboración abstracta y compleja del mundo de la cognición y del funcionamiento del pensamiento que aplica a las situaciones de la cotidianeidad. Al aterrizar esta teoría en eventos concretos conecta la complejidad del análisis micro con la abstracción que implica la operación del enmarcado.

\section{BIBLIOGRAFÍA}

Aguilar, Salvador y Funes, María Jesús (2011). «De lo macro a lo micro en el análisis relacional de Charles Tilly» en Funes, María Jesús A propósito de Tilly: conflicto, poder y acción colectiva. Madrid: Centro de Investigaciones Sociológicas; págs.:77-105. (Edición en inglés: Aguilar, Salvador y Funes, María Jesús (2016) «From Macro to Micro in the relational analysis of Charles Tilly» en Funes Rivas, María Jesús Regarding Tilly: Conflict, Power and Collective Action. American University Press; págs: 69-98).

Alexander, Jeffrey C. (1992). Las Teorías sociológicas desde la Segunda Guerra Mundial. Barcelona. Gedisa.

Beltrán, Miguel (1991). La realidad Social. Madrid: Técnos.

Benford, Robert; Snow, David; and Hunt, Scott. (2000). «Framing Processes and Social Movements: An Overview and Assessment». Annu. Rev. Sociology 2000.26, págs: 611-639.

Caballero, Juan José (1998). «La interacción social en Goffman» Revista de Investigaciones Sociológicas (REIS) no 83, págs.: 121-149.

Caneda Lowry, Santiago (2012). «El pueblo de los espejos: consumo, cuerpo y sociedad». Trabajo de Fin de Grado. Grado en Filosofía, Universidad de Coruña.

Díaz, Félix (2000). «Introducción: La ubicua relevancia de los contextos presenciales» en Sociologías de la situación. Madrid: Editorial La Piqueta, Colección Genealogía del Poder; págs: 9-38.

Freidson, Eliot (1983). «Celebrating Erving Goffman» Contemporary Sociology. Vol. $12 \mathrm{~N}^{\circ} 4$ (Julio 1983), págs: 359-362.

Goffman, Erving (1956). «Embarrassment and Social Organization» Rubor y organización social» American Journal of Sociology Vo. 62 ( ${ }^{\circ}$ 3) págs: 264-271.

- (1959). The Presentation of Self in Everyday Life, University of Edinburgh Social Sciences Research Centre. (La presentación de la persona en la vida cotidiana», Amorrortu. Buenos Aires: 1993).

- (1961). Asylums: Essays on the Social Situation of Mental Patients and Other Inmates, New York, Doubleday. (Internados. Ensayos sobre la situación social de los enfermos mentales, Amorrortu, Buenos Aires, 1994). 
- (1963). Behavior in public places: Notes on the social Organization of Gatherings. New York: Macmillan Publishing Co., Inc.

- (1963). Stigma: Notes on the Management of Spoiled Identity, Prentice-Hall. (Estigma. La identidad deteriorada, Amorrortu, Buenos Aires, 1998).

- (1967). Interaction Rituals: Essays on Face-to-Face Behavior. Anchor Books.

- (1969a). Strategic interaction. University of Pennsylvania,

— (1969b). «The Insanity of Place» (1969) Psychhiatry, Vol. XXXII (No 4); págs: 357388.

- (1974). Frame analysis: An essay on the organization of experience, London: Harper and Row. (Frame analysis: los marcos de la experiencia, Centro de Investigaciones Sociológicas, Madrid: 2006).

- (1983). «Microsociología e Historia» en Díaz, Félix (Ed.). (2000) Sociologías de la situación. Madrid: Editorial La Piqueta; págs.: 167-171. Coloquio en la Universidad de Lyon Cotidianeidad e Historicidad, Mayo de 1982.

Foucault, Michel (2015). Historia de la locura en la época clásica. México: Fondo de Cultura Económica (e.o. 1961)

- (2007). El nacimiento de la clínica. Madrid: Siglo XXI. (e.o. 1963)

- (1997). Las palabras y las cosas. Madrid: Siglo XXI. (e.o. 1966)

- (1978). Vigilar y Castigar. Madrid: Siglo XXI. (e.o. 1975)

- (1979). Microfisica del Poder. Madrid: La Piqueta (1979)

Gouldner, Alvin (1979). La crisis de la sociología occidental (e.o. 1970). Buenos Aires: Amorrortu.

Gouldner, Alvin (1970). «The Coming Crisis of Western Sociology». Londres: Heinemann.

Hernández, Francesc (1981). «Goffman y la semiótica de lo cotidiano» en Papers. Vol. 15; págs.: 127-129).

Herrera Gómez, Manuel y Soriano Miras, Rosa María (2005). «La acción social en la vida cotidiana: Erving Goffman» en Julio Iglesias de Ussel y Manuel Herrera Gómez Teorías Sociológicas de la Acción. Madrid: Tecnos; págs.: 161-194.

Manning, Philip (2000). «Credibility, Agency, and the Interaction Order.» Symbolic Interaction 23(3), págs:283-297.

Mead, George (1990). Espíritu, Persona y Sociedad. México: Paidós.

Mercado Maldonado, Assael y Zaragoza Contreras, Laura (2011). «La interacción social en el pensamiento sociológico de Erving Goffman» en Espacios Públicos. México: Universidad Autónoma del estado de México.

MILLS, C. Wrigth (1964). «Acciones situadas y vocabularios de motivos» (e. o. 1940), en Poder, política, pueblo, Fondo de Cultura Económica, México. 
Moreno Pestaña, José Luis (2015). «El poder psiquiátrico y la sociología de la enfermedad mental» en Sociología Histórica n ${ }^{\circ}$ 5; págs.: 127-164.

Ritzer, George (1993). Teoría Sociológica Contemporánea. Madrid: McGraw Hill Inc.

Sheff, Thomas J. (1990). Microsociology: Discourse, Emotion and Social Structure. Chicago: University of Chicago Press.

Tarrow, Sidney (1994). Power in Movement: Collective Action, Social Movements and Politics. Cambridge University Press.

Tilly, Charles (2006). Why: What happens when People Give Reasons and Why. Princeton University Press.

Treviño, Javier (Ed.) (2003). Goffman's Legacy. Rowman and Littlefield

Urteaga, Eguzki (2010). «Erving Goffman: vida y genealogía intelectual» en Isegoría: Revista de Filosofía moral y política $\mathrm{n}^{\circ} 42$, págs.: 149-164.

Young, Terry. Texas Women University: http://www.critcrim.org/redfeather/lectures/ 021DramaturgicalAnalysis.htm 